\title{
Exploring airshed and watershed exposure pathways as mediators of the association between proximity to surface mining and adverse birth outcomes in Central Appalachia
}

Corrine Warren Ruktanonchai ( $\sim$ cewarren6@vt.edu )

Virginia Tech: Virginia Polytechnic Institute and State University https://orcid.org/0000-0002-78893473

\section{Molly Xi McKnight}

Virginia Tech: Virginia Polytechnic Institute and State University

Lauren Grace Buttling

Virginia Tech: Virginia Polytechnic Institute and State University

Korine N Kolivras

Virginia Tech: Virginia Polytechnic Institute and State University

Leigh-Anne Krometis

Virginia Tech: Virginia Polytechnic Institute and State University

Julia M Gohlke

Virginia Tech: Virginia Polytechnic Institute and State University

\section{Research Article}

Keywords: Mediation, surface mining, maternal health, environmental health, pre-term birth, low birthweight, coal mining

Posted Date: September 30th, 2021

DOl: https://doi.org/10.21203/rs.3.rs-948330/v1

License: (c) (i) This work is licensed under a Creative Commons Attribution 4.0 International License. Read Full License 


\section{Abstract \\ Background}

Previous work has determined an association between proximity to active surface mining in coal producing counties within Central Appalachia and an increased risk of preterm birth (PTB) and low birthweight (LBW); however, the relative importance of specific exposure pathways explaining this association remains poorly understood. Multiple potential exposure pathways to surface mining activities exist during gestation, including inhalation of particulate matter (airshed exposure), or via exposure to impacted surface waters (watershed exposure). Here, we perform a mediation analysis to explore these pathways and the odds of adverse birth outcomes.

\section{Methods}

We obtained birth records acquired through health departments in WV, KY, VA and TN between 1990 and 2015. Surface mine extents for each year were identified through remotely sensed Landsat imagery. Corresponding airsheds were estimated using the HYSPLIT4 atmospheric trajectory model, while watersheds were assigned using United States Geological Survey's Watershed Boundary Dataset boundaries. We performed logistic regression to determine associations between exposure and the odds of preterm birth, low birthweight, and term low birthweight, and iteratively included within our models: a) the percent of active surface mining landcover within a $5 \mathrm{~km}$ buffer of maternal residence; $b$ ) the cumulative potential exposure to air pollutants via the airshed experienced at the maternal residence, and; c) the percent of land experiencing surface mining within the watershed of residency.

\section{Results}

Our baseline models found that active surface mining was associated with an increased odds of PTB $(1.09,1.05-1.13)$ and LBW $(1.06,1.02-1.11)$, while controlling for significant predictors. When mediators were added to the base model, the association between active mining and birth outcomes was reduced (PTB: 1.04, 0.99 - 1.09; LBW 1.04, 0.99 - 1.10), while the odds of PTB and LBW increased with airshed exposure (PTB: 1.14, 1.11 - 1.18; LBW: 1.06, 1.03 - 1.10).

\section{Conclusions}

Results were consistent with a hypothesis of mediation via airshed, but suggested mediation via watershed was less likely. These results suggest that air pollution resulting from surface mining activities may be the primary exposure pathway explaining the association between maternal residence proximity to active surface mining and PTB and LBW. 


\section{Introduction}

Communities within the Central Appalachia region, containing areas within Virginia, West Virginia, Kentucky and Tennessee, experience some of the most severe economic and health disparities across the United States (1). While poverty has generally decreased since the mid-1900's, the region continues to lag behind national poverty estimates, with increased rates of unemployment, lower levels of post-secondary education, and lower life expectancy $(2,3)$. Surface mining has become more widespread since the 1990s, and represented over 60\% of coal mined within 2019 (4). Within Central Appalachia, there were nearly double the amount of surface mines as underground mines in 2019, despite relatively similar levels of coal production (5). Surface mining disrupts the local environment, where forest is cleared, rocks and topsoil are loosened through explosives to expose the underlying coal seams, and the resultant rubble is dumped into nearby valleys and headstreams $(4,6)$.

These surface mining activities have been previously associated with adverse health outcomes $(1,7)$. For example, a county-level cross-sectional analysis found higher rates of respiratory disease, hypertension and kidney disease among populations living in counties with greater coal production, as compared to those living further away from coal mining activities (8). However, the relative importance of the exposure pathways underlying these associations remain less clear. Previous research outlining the public health impacts of surface mining activities (7) has proposed two possible biological mechanisms to explain these relationships. Firstly, there is evidence that inhalation of particulate matter is increased near surface mining activities $(9,10)$. Within Central Appalachia, surface mining activities result in increased emissions of acidic aerosols such as sulfur dioxide and nitrous dioxide (11), as well as particulate matter smaller than 10 microns in diameter $\left(\mathrm{PM}_{10}\right)$ as a result of trucks hauling coal (12). Studies have found that particulate matter collected from nearby surface mines results in increased inflammatory responses

and vascular tissue damage in a rodent model $(9,10)$ and increased carcinogenic markers in human lung cells (13), which is consistent with the higher rates of cardiovascular and lung disease observed in the region (10). Exposure to air pollution is known to result in a range of adverse health outcomes across the life cycle, including adverse birth outcomes $(14,15)$.

Secondly, exposure to heavy metals in drinking water contaminated by surface mining activities has also been proposed as a causal pathway linking adverse health outcomes and proximity to surface mining activities (7). However, little research is available that quantifies the in situ exposure to heavy metals, water quality and sources of drinking water used within Appalachia (1). While associations between metals in water and increased rates of cancer and chronic disease have been noted, researchers have called for a more thorough investigation of these associations linked specifically to exposure to waterborne contaminants and dose of exposure, while controlling for behavioral risk factors such as tobacco use (7). Despite this lack of evidence, other studies within the field of aquatic ecology have noted elevated concentrations of heavy metals and nonmetallic ions downstream of active and historic surface mining activities, resulting in loss of aquatic biodiversity within Appalachian headwater streams (6). Given that these streams are inevitably hydrologically connected to source waters for regional drinking 
water supplies, degradation of aquatic ecological health potentially indicates important concurrent public health risks.

Here, we build on previous research (16) with the aim to explore airshed and watershed exposure pathways as potential mediators of the association observed between proximity to surface mining activities and adverse birth outcomes. Specifically, we undertake a mediation analysis within a generalized linear modelling framework to examine the odds of preterm birth, low birthweight, and term low birthweight outcomes as predicted by maternal proximity to surface mining activities during gestation from 1990 - 2015, overlaying surface mine airshed and watershed boundaries. To undertake these analyses, we use geolocated birth records spanning four states in the Central Appalachia region, representing nearly 200,000 births over 2.5 decades. Specifically, we hypothesize that increased odds of preterm birth and low birthweight associated with proximity to surface mining activities during gestation may be mediated by airshed or watershed pathways, or both, and examine the additive effects of these mediators on the models.

\section{Methods}

\section{Data}

We obtained birth records for ZIP code catchment areas within four states across Central Appalachia, provided by departments of health in Kentucky (KY), Tennessee (TN), Virginia (VA), and West Virginia (WV) (Figure 1). This dataset is described in detail in (16); briefly, a total of 409,394 birth records were obtained from departments of health and geocoded to street address of reported maternal address. Due to missingness in street addresses with many records reporting only mailing addresses (rural route or P.O. box), particularly for earlier years of the dataset, this resulted in a final dataset comprising 194,084 births between 1990 and 2015 with street-level data (16). Yearly surface mining land cover areas were obtained from Marston and Kolivras (17) for the years 1986 through 2015 using 30 m resolution Landsat remote sensing imagery. This dataset uses remote sensing technology and satellite imagery to quantify changes in the extent of surface mining areas over the corresponding years. Specifically, for each year, barren land on which vegetation had been removed was identified, and pixels that were tied to other types of land disturbance, such as clear cutting of timber, were excluded. Remaining barren pixels lying within areas permitted for mining within the USGS-defined Appalachian coalfields were designated as places where active mining was likely taking place. Active surface mining was delineated from pre- and post-mining areas through classification of vegetation, where actively mined areas tend to be barren while postmining areas tend to show some revegetation through reclamation efforts. Validation with randomly placed points on $1 \mathrm{~m}$ resolution aerial photography found an overall accuracy of $88 \%$. Lastly, mined areas $<40$ acres in size were removed from the analysis, as the Office of Surface Mining Reclamation and Enforcement reported that economically viable mines are generally at least 40 acres in size (18).

Figure 1. Study area (red) and surface mining coal production (thousand tons) at the county level for 1993 (top) and 2015 (bottom). Coal production data for 2015 and 1993 were obtained from (19) and (20) 
Airsheds for each of the active surface mine in each year of analysis were estimated using the HYbrid Single-Particle Lagrangian Integrated Trajectory (HYSPLIT4) atmospheric trajectory model (21), which uses meteorological data to compute atmospheric trajectories, particle dispersion, and air concentrations. Detailed methods using HYSPLIT4 to characterize airsheds of surface mines are described in further detail in McKnight et al. (22). Briefly, we modeled individual airsheds of each active surface mine in the study area. The results of this process were raster data sets comprised of frequency values relating to air movement from surface mines per gridded cell. To quantify each birth record's total exposure from all mines, we summed the frequency values of all airsheds extracted at each birth record's location for the cumulative amount of air from surface mines experienced at the maternal residential address. Lastly, watersheds were classified using 10-digit hydrologic unit codes (HUC10) within the United States Geological Survey's Watershed Boundary Dataset, which represent the areal extent of surface water drainage using an aggregate collection of hydrologic unit data (23) and amount of active surface mining within watersheds for each year of the study period was calculated.

\section{Analysis}

We employed mediation analyses to explore the potential exposure pathways that could explain associations between living in close proximity to active surface mining activities and increased odds of preterm birth and low birthweight described in (16), accounting for pre-mining differences and additional individual-level covariates available on birth records. Mediation analyses are helpful in exploring the underlying mechanisms underpinning a known relationship between an exposure and outcome (24). Generally, mediation is suggested when four criteria are met, as outlined in Table 1 (25).

Table 1

Mediation criteria, adapted from (25)

\section{Criteria Assessed}

1 Independent variable significantly influences the mediator

2 Independent variable significantly influences the dependent variable (in absence of the mediator)

3 Mediator significantly and uniquely influences the dependent variable

4 The effect of the independent variable on the dependent variable shrinks with addition of the mediator

\section{Statistical Test(s) Used}

Unadjusted regression model Sobel test

Adjusted regression model

Our independent variable of interest was the percent of land within a $5 \mathrm{~km}$ radius of the maternal residential address that was designated as an active surface mine during the majority year of gestation. Our dependent variables of interest included 1) preterm birth (PTB), defined as birth before 37 weeks of 
gestation; 2) low birthweight (LBW), defined as birthweight less than 2,500 grams; and 3) term low birthweight (TLBW), defined as birth occurring at $\geq 37$ weeks gestation and birthweight less than 2,500 grams. Using these criteria, we tested whether mediation between proximity to active surface mining activities during the year containing the majority of the pregnancy (majority gestation year) and these adverse birth outcomes occurred via the airshed pathway or the watershed pathway. We quantified these potential mediators (Figure 2), respectively, as: 1 ) the cumulative potential exposure to air pollutants via the airshed experienced at the maternal residential address during the majority gestation year, and 2) the percent of land experiencing active surface mining within the watershed of residency during the majority gestation year. The cumulative potential exposure to airborne pollutants via the airshed is outlined in further detail within Mcknight et al. (22); briefly, these values represent the cumulative frequency of air originating from active surface mines, as modeled via the HYSPLIT4 atmospheric trajectory model. Residential addresses associated with higher values of this airshed model have higher potential exposure to surface mining air pollution, including fine particulate matter.

Figure 2. Directed acyclic graph outlining potential mediators of the association between surface mining and adverse birth outcomes.

We firstly employed a Sobel test using the bda package in R software to quantify whether mediators significantly influenced the relationship between the independent and dependent variables $(26,27)$. We further performed a generalized linear model regression analysis using the stats package within the base R software. Covariates within our model included categorical variables for maternal age('18 - 35 years', <18 years',> 35 years'), highest education attained by the mother at the child's birth ('8th grade or less', '9th - 12th grade (includes high school graduates)', 'Post high-school education (with or without degree)'), race ('White', 'Black', 'Other'), ethnicity ('Hispanic', 'Not Hispanic'), self-reported tobacco use during pregnancy ('Yes','No'), sex of the child ('Male', 'Female'), payment type for birth medical services ('Medicaid', 'Private Insurance', 'Self-Pay', 'Other'), state ('Kentucky', 'Tennessee', 'Virginia', and 'West Virginia'), and continuous percent of land within $5 \mathrm{~km}$ of maternal residence that was not actively experiencing mining activities during the majority gestation year, but would be subsequently mined in later years (referred to as 'pre-mining' activities), to account for any temporal baseline difference prior to active mining. Because mining activities tend to show spatial autocorrelation (e.g., active mining tends to move progressively across the landscape and is therefore closely correlated with pre-mining landcover), we further included an interaction term between the amount of pre-mined land and surface mining land within a $5 \mathrm{~km}$ buffer of maternal residence. Lastly, to allow for non-linear temporal trends observed within the data, we included a spline with 4 degrees of freedom in the year covariate using the splines package within R software. This model builds on the model detailed in (16), which can generally be specified as:

$$
\operatorname{logit}\left(y_{i}\right)=\beta_{0}+\beta_{m} M_{i}+\beta_{t} T_{i}+\beta_{m t} M_{i} * T_{i}+(b s(t))+\sum_{k} \delta_{k} x_{i k}
$$


where logit $\left(y_{i}\right)$ represents the odds of an adverse outcome (PTB, LBW, and TLBW) occurring for a given woman's birth, $i ; M_{i}$ represents the $\%$ of pre-mining land area within a $5 \mathrm{~km}$ buffer of the maternal residence of individual $i ; T_{j}$ represents the $\%$ of surface mining area within a $5 \mathrm{~km}$ buffer of the maternal residence of individual $i ; \beta_{m t} M_{i} * T_{i}$ represents the interaction effect of having land within $5 \mathrm{~km}$ of the maternal residence of individual, $i$, that is both likely actively being mined (active mining) and will subsequently be mined (pre-mining); $b s(t)$ represents a non-linear spline with 4 degrees of freedom to fit temporal trends in the data; and $x_{i k}$ represents the suite of fixed covariates $K$ as outlined above (16). To explore hypothesized mediation pathways, we tested three model types which iteratively built on each other (Figure 3) (27). Our base adjusted model (Model 0 ) included the suite of fixed effects described above, including the independent variable of interest (e.g., \% surface mining activities in a $5 \mathrm{~km}$ buffer). Model 1 included the same suite of variables as Model 0 , with the addition of the airshed mediator variable, while Model 2 further included both the airshed and watershed mediators. We report model performance metrics, including McFadden's pseudo- $\mathrm{R}^{2}$ statistic, Akaike Information Criterion (AIC), and mean adjusted error (MAE) and root-mean squared error (RMSE) measures. AIC represents a measure of model predictive power as a trade-off with model complexity, with lower values generally representing models with better fit (28). MAE and RMSE represent model precision and bias, with values closer to zero representing better model fit, while pseudo- $\mathrm{R}^{2}$ values represent variance explained by the model, with values between $0.2-0.4$ representing reasonable model fit across a range of applications (29-32). Lastly, we converted regression results to probabilities using the following equation:

$$
P=\frac{1}{1+e^{-\left(\beta_{0}+\beta_{1} X_{1}+\beta_{2} X_{2}+\cdots\right)}}
$$

Figure 3. Model diagrams outlining the iterative model building process. Iterative models were built for each dependent variable (e.g., PTB, $L B W$, and TLBW).

\section{Results}

\section{Sobel test}

Results of the Sobel test suggesting evidence of whether mediation is occurring are presented in Table 2 . For each dependent variable of interest, we conducted an independent Sobel test exploring whether mediation is occurring via the airshed pathway $(M=$ air $)$ as well as the watershed pathway $(M=$ water $)$, with the independent variable of interest defined as proximity to surface mining. Evidence suggested that mediation was occurring via the airshed pathway for preterm birth and low birthweight outcomes $(p<$ 0.001), while evidence was less clear for mediation of term low birthweight. There was further evidence suggesting that mediation may be occurring via the watershed pathway for preterm birth $(p=0.012)$ but mediation was less clear for other birth outcomes. 
Table 2

Sobel test exploring the mediation via airshed and watershed pathways from surface mining operations on birth outcomes

\begin{tabular}{|lcl|}
\hline & Z-value & Significance \\
\hline$M=$ air, $X$ = surface mining & \\
\hline Preterm birth & 14.20 & $9.78 \mathrm{e}-46$ *** \\
\hline Low birthweight & 5.66 & $1.53 \mathrm{e}-08$ *** \\
\hline Term low birthweight & 1.12 & 0.261 \\
\hline$M=$ water, $X$ = surface mining \\
\hline Preterm birth & 2.522 & 0.012 * \\
\hline Low birthweight & 1.158 & 0.247 \\
\hline Term low birthweight & 1.857 & 0.063 \\
\hline Signif. codes: 0 '***' 0.001 '**' 0.01 '*' \\
\hline
\end{tabular}

\section{Unadjusted model results}

We firstly explored unadjusted model results for each dependent variable of interest, as outlined in Table 3. Specifically, the results of these unadjusted models are used to test whether the independent variable significantly influenced the mediator, a key criterion indicating mediation. Towards this, we found that proximity to surface mining strongly influenced both hypothesized mediator pathways $(p<0.001)$. We further conducted unadjusted models on the dependent variables of interest before conducting adjusted models. Across all outcomes, both mediation pathways were generally strongly significant, with the exception of term low birthweight. Of note, results tended to be more strongly significant among the airshed mediation pathways, as opposed to the watershed mediation pathway. 
Table 3

Unadjusted model predicting birth outcomes by airshed and watershed pollution exposure

\begin{tabular}{|c|c|c|c|}
\hline \multicolumn{4}{|l|}{ Preterm Birth } \\
\hline Covariates & $\beta$ & SE & Significance \\
\hline PTB air & 0.138 & 0.009 & $<2 \mathrm{e}-16 * \star \star$ \\
\hline PTB water & 0.061 & 0.015 & $2.59 \mathrm{e}-05 * \star \star$ \\
\hline \multicolumn{4}{|l|}{ Low Birthweight } \\
\hline LBW air & 0.069 & 0.011 & 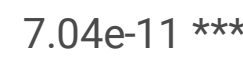 \\
\hline LBW water & 0.047 & 0.017 & $0.00473 * \star$ \\
\hline \multicolumn{4}{|l|}{ Term Low Birthweight } \\
\hline TLBW air & 0.028 & 0.017 & 0.0928 \\
\hline TLBW water & 0.069 & 0.026 & $0.00865 * *$ \\
\hline \multicolumn{4}{|l|}{ Mediators } \\
\hline surface mining $\sim$ air & 0.228 & 0.002 & $<2 \mathrm{e}-16 \star \star \star$ \\
\hline surface mining $\sim$ water & 0.729 & 0.002 & 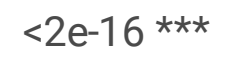 \\
\hline \multicolumn{4}{|c|}{ Signif. codes: 0 ‘ $\star \star \star \star^{\prime} 0.001^{\prime} \star \star^{\prime} 0.01^{\prime \prime} \star^{\prime}$} \\
\hline
\end{tabular}

\section{Adjusted model results}

To test the remaining criteria (Table 1) for whether mediation occurred between adverse birth outcomes and proximity to surface mining, we iteratively performed a generalized linear model with the addition of mediating variables. Full model results are listed in supplemental tables $\$ 1-\mathrm{S} 3$. Overall, in our baseline models (e.g., without the addition of mediation pathways), we found that sociodemographic characteristics such as older age ( $>35$ years), self-reported tobacco use during pregnancy, having a female child, race, and type of payment used to cover birth services (e.g., Medicaid and 'Other') were significantly predictive of increased odds of preterm birth, low birthweight, and term low birthweight outcomes. We further found significant differences in the odds of preterm birth across states, with women giving birth in Central Appalachian counties within Tennessee at higher odds of having a preterm birth and women giving birth in Virginia at lower odds, as compared to women giving birth in Kentucky. Across all outcomes, self-reported tobacco use during pregnancy resulted in the highest odds ratios of adverse birth outcomes as compared to other sociodemographic characteristics within the model, particularly for term low birthweight (OR: 3.06, 95\% Cl: $2.80-3.35)$.

To explore mediation pathways, we firstly examined whether the independent variable significantly influenced the dependent variables in absence of the mediators (mediation criterion \#2), denoted as Model 0 . We found proximity to surface mining significantly influenced preterm birth, such that a $1 \%$ 
increase in the amount of land within a $5 \mathrm{~km}$ buffer around the maternal address being mined was associated with a $9 \%$ increase in the odds of having preterm birth (OR: $1.09 ; 1.05-1.13$ ) and $6 \%$ increase in the odds of low birthweight (OR: 1.06, $1.02-1.11$ ) In practical terms, the highest percentage of surface mining within a $5 \mathrm{~km}$ buffer surrounding maternal address was observed to be just over $15 \%$, with a mean of under $1 \%(0.13 \%)$.

To test whether mediators significantly and uniquely impacted the dependent variable (mediation criterion \#3), we added the airshed pathway variable (Model 1) and watershed pathway variable (Model $2)$. The airshed pathway was strongly significant in the preterm birth model $(p<0.001)$ and low birthweight model $(p=0.004)$, even after the addition of the watershed pathway in Model 2. Evidence of watershed mediation was less clear among all outcomes, and among term low birthweight, evidence of mediation via either airshed or watershed pathways was lacking. Lastly, Figure 4 explores whether the effect of the independent variable was reduced after the addition of the mediating variables, showing the odds ratio and $95 \%$ confidence intervals of proximity to surface mining in predicting each birth outcome. Blue lines represent the base model (Model 0 ) with no mediation variables, while green represents the addition of the airshed variable (Model 1) and blue represents the addition of the watershed variable (Model 2). Across all outcomes, the effect of proximity to surface mining on predicting preterm birth, low birthweight, and term low birthweight was reduced with the addition of the hypothesized mediators. Interestingly, the effect of surface mining across outcomes became non-significant in the final models (airshed plus watershed exposure; red), but remained significant among preterm birth and low birthweight outcomes with the addition of the airshed pathway alone (green). Of note, proximity to surface mining was not significantly predictive of term low birthweight across models (Table S3), but the effect was still reduced with the addition of mediators (Figure 4).

Figure 4. Odds ratios for proximity to active surface mining in predicting adverse birth outcomes. Blue represents the baseline model (no mediators); green represents the addition of the airshed mediator to the baseline model; red represents the addition of the watershed mediator to the baseline + airshed mediator model. Dots represent point estimates of odds ratios and lines represent upper and lower $95 \%$ confidence intervals. Lines crossing 1 indicate non-significance.

Lastly, those living in areas with the highest amount of active mining activities ( $15 \%$ of $5 \mathrm{~km}$ buffer being designated as surface mining), and having the highest airshed and watershed exposure, had a probability of nearly 1 in 4 (24.5\%) of having a preterm birth, as compared to $9.3 \%$ among women with no exposure to surface mining activities within $5 \mathrm{~km}$ of their residence. Women having the highest exposure further had an $8.9 \%$ probability of experiencing low birthweight, as compared to only a $4.2 \%$ probability among those not living near surface mining. The relative risk between women experiencing the highest amount of surface mining versus the lowest was 2.26 for preterm birth and 2.13 for low birthweight, suggesting that those living near the highest amount of surface mining remain at increased risk of adverse birth outcomes.

\section{Discussion}


Previous studies have suggested proximity to surface mining activities is associated with an increased odds of adverse health outcomes (3), including adverse birth outcomes (16), and birth defects $(33,34)$. The direct and indirect causal pathways underlying these associations, however, remain less clear (35). Here, we aimed to clarify these associations by exploring hypothesized mediating pathways linking exposure to coal mining activities and resultant birth outcomes.

Overall, we generally found strong evidence that more proximate exposures to active surface mining byproducts resulted in higher odds of preterm birth and low birthweight outcomes, which was mediated along the airshed pathway. Specifically, the airshed pathway met all four mediation criteria among these outcomes (Table 1): 1) the airshed pathway was significantly associated with active surface mining (Table 3$)$; 2) proximity to active surface mining was significantly associated with both preterm birth and low birthweight outcomes in the absence of the airshed pathway (Tables S1 and S2, Model 0); the airshed pathway significantly and uniquely affected preterm birth and low birthweight outcomes (Tables S1 and S2, Model 1); and, 4) the effect of proximity to active surface mining activities on both preterm birth and low birthweight outcomes was reduced with the addition of the airshed pathway. Evidence of mediation via airshed was less clear for term low birthweight. While criteria 1 and 4 were met, the effect of proximity to active surface mining on term low birthweight was not significant to suggest an association. While mediation was not clear, this outcome was strongly explained by maternal age at birth, race, self-reported tobacco use, payment type for birth services and child sex, with the highest odds of term low birthweigh among those reporting tobacco use (OR: 3.06, $2.80-3.35)$.

Evidence for mediation along the watershed pathway across outcomes was also less clear. While the watershed pathway was significantly associated with active surface mining, and the effect of surface mining on the dependent variables were generally reduced with its addition, the watershed pathway was not significantly and uniquely associated with the adverse birth outcomes, as evidenced in Tables S1 S3 (Model 2). These findings are in line with results from the Sobel test (Table 2), which suggested mediation along the airshed pathway for preterm birth and low birthweight, but not along the watershed pathway.

These findings suggest that the causal pathway underlying the association between active surface mining and preterm birth and low birthweight outcomes likely occurs via exposure to air pollution, potentially influenced by particulate matter emissions from coal mining activities. Evidence suggested mediation via the watershed pathway was less likely, which is unsurprising given the pathway between water pollution and drinking water is more complex than exposure to air pollution. For example, the majority of residents in this region are served by municipal drinking water, which is treated prior to distribution and consumption (36); adverse changes to source water quality will only have an impact if these treatment systems fail. In addition, it is well-documented that changes in household water quality can alter consumption source patterns: specific to this region, a residential survey conducted in West Virginia found that perceptions of poor water quality within the area resulted in behavior changes among the respondents, such as consuming bottled water over tap water (37). Exposure to developmental toxicants via contamination of surface or groundwaters therefore represents a potential indirect causal 
pathway, which might be alleviated by water treatment prior to reaching the household tap or alternative drinking water sources (e.g., bottled water).

These analyses should be considered within the context of their associated limitations. Firstly, we did not directly measure airshed or watershed exposure at the individual level, but instead used proxy atmospheric models and geological boundaries. For example, we used satellite imagery to designate temporal surface mining activities based on mine permits and barren land cover; while this classification likely represents active surface mining activities because the change in landcover due to surface mining is stark, it does not capture on-the-ground information about mining activities and air or water emissions. Using these proxies therefore does not quantify an individual's actual exposure to air and water pollutants, heavy metals, etc. and future research could aim characterize individual exposure via prospective studies. Secondly, our analyses are limited to women with an identifiable street address (e.g., excluding post office boxes, etc.). It was necessary, however, to restrict our analyses at this level in order to link individual births to surface mining airsheds and watersheds. Our previous analyses using ZIP code level exposures that allowed for inclusion of most birth records in the dataset showed that ZIP code and street-level analyses provided similar results (16), increasing our confidence that the current analysis is minimally biased due to this limitation. Thirdly, our analyses rely on secondary data sources and are therefore limited to socioeconomic and demographic characteristics existing on birth records. Namely, tobacco use within these records was self-reported, which may not represent actual tobacco use in pregnancy. Further, other important characteristics such as illicit substance use, household income, etc. were not included in our analyses, as these covariates did not exist within the data. Future research could incorporate additional area-level sociodemographic characteristics within a hierarchical framework.

\section{Conclusions}

Surface mining activities have dramatically altered the Central Appalachia landscape, and the environmental and public health consequences are still being characterized. While previous literature links proximity to surface mining activities and resultant adverse birth outcomes, the causal pathways underlying these associations remain poorly understood. Our study represents a novel mediation analysis using nearly 200,000 geolocated birth records spanning four states in Central Appalachia from 1990 2015 to explore airshed and watershed exposure pathways as mediators of the relationship between surface mining activities and adverse birth outcomes. Our findings suggest that the airshed pathway mediates the association between surface mining activities and preterm birth and low birthweight outcomes, but evidence of mediation via the watershed pathway was less clear.

\section{Declarations}

\section{Ethics approval and consent to participate}

This study was reviewed and approved by the Virginia Tech Institutional Review Board (IRB) (No. 16-898), Virginia Department of Health IRB (No. 40221), West Virginia Department of Health and Human 
Resources, Kentucky Cabinet for Health and Family Services IRB (No. FY17-23), and Tennessee Department of Health IRB (No. 972154). Tennessee Department of Health data used in this study were obtained from the vital statistics program, Tennessee Department of Health (TDH). Use of these data does not imply TDH agrees or disagrees with any presentations, analyses, interpretations, or conclusions herein.

\section{Consent for publication}

Individual consent was waived, as these analyses used secondary datasets.

\section{Availability of data and materials}

Data use agreements with state health agencies prohibit authors from sharing birth record data used in the analysis. Satellite-derived datasets are publicly available, or available on request. Code required to replicate results are available upon request.

\section{Competing interests}

The authors declare that they have no competing interests.

\section{Funding}

Supported by a grant from the National Institute of Environmental Health Sciences (R21ES028396).

\section{Authors' contributions}

CWR conducted all analyses and drafted the initial version of the manuscript. All authors provided edits and feedback on subsequent versions of the manuscript. MM, LB, KK, and LAK helped to produce and compile the datasets used in these analyses, including births records data and satellite-derived data. JG provided supervision and feedback on the analyses conducted and all versions of the manuscript. All authors read and approved the final manuscript.

\section{Acknowledgements}

The authors would like to acknowledge the contributions made to compiling the datasets used in these analyses by the following individuals: M Marston, L Marr, and E Smith. The authors would also like to thank A Mendrinos and B Ramesh for their feedback while these analyses were being conducted.

\section{References}

1. Krometis L-A, Gohlke J, Kolivras K, Satterwhite E, Marmagas SW, Marr LC. Environmental health disparities in the Central Appalachian region of the United States. Reviews on Environmental Health. 2017 Sep 1;32(3):253-66. 
2. PDA INC, APPALACHIAN REGIONAL COMMISSION, THE CECIL G. SHEPS CENTER FOR HEALTH. SERVICES RESEARCH. Health Disparities in Appalachia [Internet]. Washington, DC, USA: APPALACHIAN REGIONAL COMMISSION; 2017 Aug [cited 2021 Jul 28]. (Creating a Culture of Health in Appalachia: Disparities and Bright Spots). Available from: https://www.arc.gov/wpcontent/uploads/2020/06/Health_Disparities_in_Appalachia_August_2017.pdf.

3. Gohlke JM. Human Health in Coalfield Communities of Appalachia. In: Zipper CE, Skousen J, editors. Appalachia's Coal-Mined Landscapes: Resources and Communities in a New Energy Era [Internet]. Cham: Springer International Publishing; 2021 [cited 2021 Jul 27]. p. 311-36. Available from: https://doi.org/10.1007/978-3-030-57780-3_12.

4. U.S. Energy Information Administration (EIA). Coal and the environment [Internet]. [cited 2021 Sep 8]. Available from: https://www.eia.gov/energyexplained/coal/coal-and-the-environment.php.

5. US Energy Information Administration. Annual Coal Report 2019. Washington, DC, USA: US Department of Energy; 2019. p. 87.

6. Palmer MA, Bernhardt ES, Schlesinger WH, Eshleman KN, Foufoula-Georgiou E, Hendryx MS, et al. Mountaintop Mining Consequences. Science. 2010 Jan 8;327(5962):148-9.

7. Hendryx M. The public health impacts of surface coal mining. The Extractive Industries and Society. 2015 Dec 1;2(4):820-6.

8. Hendryx M, Ahern MM. Relations Between Health Indicators and Residential Proximity to Coal Mining in West Virginia. Am J Public Health. 2008 Apr 1;98(4):669-71.

9. Nichols CE, Baseler WA, Thapa D, LaFata G, Croston TL, Shepherd DL, et al. Mountain-top mining particulate matter exposure increases markers of mitochondrially-driven apoptosis in rat cardiac tissue. The FASEB Journal. 2012;26(S1):1036.15-1036.15.

10. Knuckles TL, Stapleton PA, Minarchick VC, Esch L, McCawley M, Hendryx M, et al. Air Pollution Particulate Matter Collected from an Appalachian Mountaintop Mining Site Induces Microvascular Dysfunction. Microcirculation. 2013;20(2):158-69.

11. Spengler JD, Koutrakis P, Dockery DW, Raizenne M, Speizer FE. Health effects of acid aerosols on North American children: air pollution exposures. Environ Health Perspect. 1996 May;104(5):492-9.

12. Aneja VP, Isherwood A, Morgan P. Characterization of particulate matter (PM10) related to surface coal mining operations in Appalachia. Atmos Environ. 2012 Jul;1:54:496-501.

13. Luanpitpong S, Chen M, Knuckles T, Wen S, Luo J, Ellis E, et al. Appalachian Mountaintop Mining Particulate Matter Induces Neoplastic Transformation of Human Bronchial Epithelial Cells and Promotes Tumor Formation. Environ Sci Technol. 2014 Nov 4;48(21):12912-9.

14. Dadvand P, Parker J, Bell ML, Bonzini M, Brauer M, Darrow LA, et al. Maternal Exposure to Particulate Air Pollution and Term Birth Weight: A Multi-Country Evaluation of Effect and Heterogeneity. Environmental Health Perspectives. 2013 Mar;121(3):267-373.

15. Gray SC, Edwards SE, Schultz BD, Miranda ML. Assessing the impact of race, social factors and air pollution on birth outcomes: a population-based study. Environ Health. 2014;13:4. 
16. Buttling LG, McKnight MX, Kolivras KN, Ranganathan S, Gohlke JM. Maternal proximity to Central Appalachia surface mining and birth outcomes. Environ Epidemiol [Internet]. 2021 Jan 25 [cited 2021 May 4];5(1). Available from: https://www.ncbi.nlm.nih.gov/pmc/articles/PMC7939414/.

17. Marston ML, Kolivras KN. Identifying Surface Mine Extent Across Central Appalachia Using Time Series Analysis, 1984-2015. International Journal of Applied Geospatial Research (IJAGR). 2021;12(1):38-52.

18. United States Office of Surface Mining Reclamation and Enforcement. Valid existing rights proposed revisions to the permanent program regulations implementing section 522(E) of the Surface Mining Control and Reclamation Act of 1977 and proposed rulemaking clarifying the applicability of section 522(E) to subsidence from underground mining: environmental impact statement [Internet]. Washington, DC, USA; 1999 [cited 2021 Sep 3]. Available from: https://onlinebooks.library.upenn.edu/webbin/book/lookupid?key=ha100977853.

19. US Energy Information Administration. Annual Coal Report 2015 [Internet]. Washington, DC, USA: US Department of Energy; 2016 Nov [cited 2021 Sep 7]. Available from: https://www.eia.gov/coal/annual/archive/05842015.pdf.

20. US Energy Information Administration. Coal Industry Annual 1993. Washington, DC, USA: US Department of Energy; 1994 Dec. p. 287.

21. Draxler RR, Hess GD. Description of the HYSPLIT4 Modeling System. Silver Spring: NOAA Air Resources Laboratory; 1997 Dec. p. 31. (NOAA Technical Memorandum ERL ARL-224).

22. McKnight MX, Kolivras KN, Buttling LG, Gohlke JM, Marr LC, Pingel TJ, et al. Associations Between Surface Mining Airsheds and Birth Outcomes in Central Appalachia at Multiple Spatial Scales. Spatial and Spatio-temporal Epidemiology. in review.

23. United States Department of Agriculture-Natural Resources Conservation Service (USDA-NRCS). United States Geological Survey (USGS), Environmental Protection Agency (EPA). HUC10: USGS Watershed Boundary Dataset of Watersheds [Internet]. 2017 [cited 2021 May 10]. Available from: https://developers.google.com/earth-engine/datasets/catalog/USGS_WBD_2017_HUC10.

24. VanderWeele TJ. Mediation Analysis: A Practitioner's Guide. Annu Rev Public Health. 2016 Mar 18;37(1):17-32.

25. Preacher KJ, Hayes AF. Asymptotic and resampling strategies for assessing and comparing indirect effects in multiple mediator models. Behavior Research Methods. 2008 Aug 1;40(3):879-91.

26. Baron RM, Kenny DA. The moderator-mediator variable distinction in social psychological research: conceptual, strategic, and statistical considerations. J Pers Soc Psychol. 1986 Dec;51(6):1173-82.

27. Mackinnon DP, Dwyer JH. Estimating Mediated Effects in Prevention Studies. Eval Rev. 1993 Apr 1;17(2):144-58.

28. Bozdogan $\mathrm{H}$. Model selection and Akaike's Information Criterion (AIC): The general theory and its analytical extensions. Psychometrika. 1987 Sep 1;52(3):345-70.

29. Bosco C, Alegana V, Bird T, Pezzulo C, Bengtsson L, Sorichetta A, et al. Exploring the high-resolution mapping of gender-disaggregated development indicators. Journal of The Royal Society Interface. 
2017 Apr;30(129):20160825. 14(.

30. Ruktanonchai CW, Nilsen K, Alegana VA, Bosco C, Ayiko R, Seven Kajeguka AC, et al. Temporal trends in spatial inequalities of maternal and newborn health services among four east African countries, 1999-2015. BMC Public Health. 2018 Dec 4;18(1):1339.

31. Smith TJ, McKenna CM. A Comparison of Logistic Regression Pseudo R2 Indices. Multiple Linear Regression Viewpoints. 2013;39(2):10.

32. McFadden D. Conditional logit analysis of qualitative choice behavior. In: Frontiers in Econometrics [Internet]. Zarembka P. Academic Press; 1974 [cited 2021 Aug 18]. p. 105-42. Available from: https://eml.berkeley.edu/reprints/mcfadden/zarembka.pdf.

33. Ahern MM, Hendryx M, Conley J, Fedorko E, Ducatman A, Zullig KJ. The association between mountaintop mining and birth defects among live births in central Appalachia, 1996-2003. Environmental Research. 2011 Aug 1;111(6):838-46.

34. Ahern M, Mullett M, MacKay K, Hamilton C. Residence in Coal-Mining Areas and Low-Birth-Weight Outcomes. Matern Child Health J. 2011 Oct 1;15(7):974-9.

35. Lamm SH, Li J, Robbins SA, Dissen E, Chen R, Feinleib M. Are residents of mountain-top mining counties more likely to have infants with birth defects? The west virginia experience. Birth Defects Research Part A: Clinical Molecular Teratology. 2015;103(2):76-84.

36. Hughes J, Whisnant R, Weller L, Eskaf S, Richardson M, Morrissey S, et al. Drinking Water and Wastewater Infrastructure in Appalachia. Appalachian Regional Commission; p. 150.

37. McSpirit S, Reid C. Residents' Perceptions of Tap Water and Decisions to Purchase Bottled Water: A Survey Analysis from the Appalachian, Big Sandy Coal Mining Region of West Virginia. Society \& Natural Resources. 2011 Mar 21;24(5):511-20.

\section{Abbreviations}

AIC

$\mathrm{Cl}$

HYSPLIT4

HUC

KY

LBW

MAE

MGY

$\mathrm{OR}$
Akaike Information Criterion

Confidence interval

HYbrid Single-Particle Lagrangian Integrated Trajectory

Hydrologic unit code

Kentucky

Low birthweight

Mean adjusted error

Majority gestation year

Odds ratio 
RMSE

TLBW

TN

VA

WV

Figures
Root mean square error

Term low birthweight

Tennessee

Virginia

West Virginia 
1993

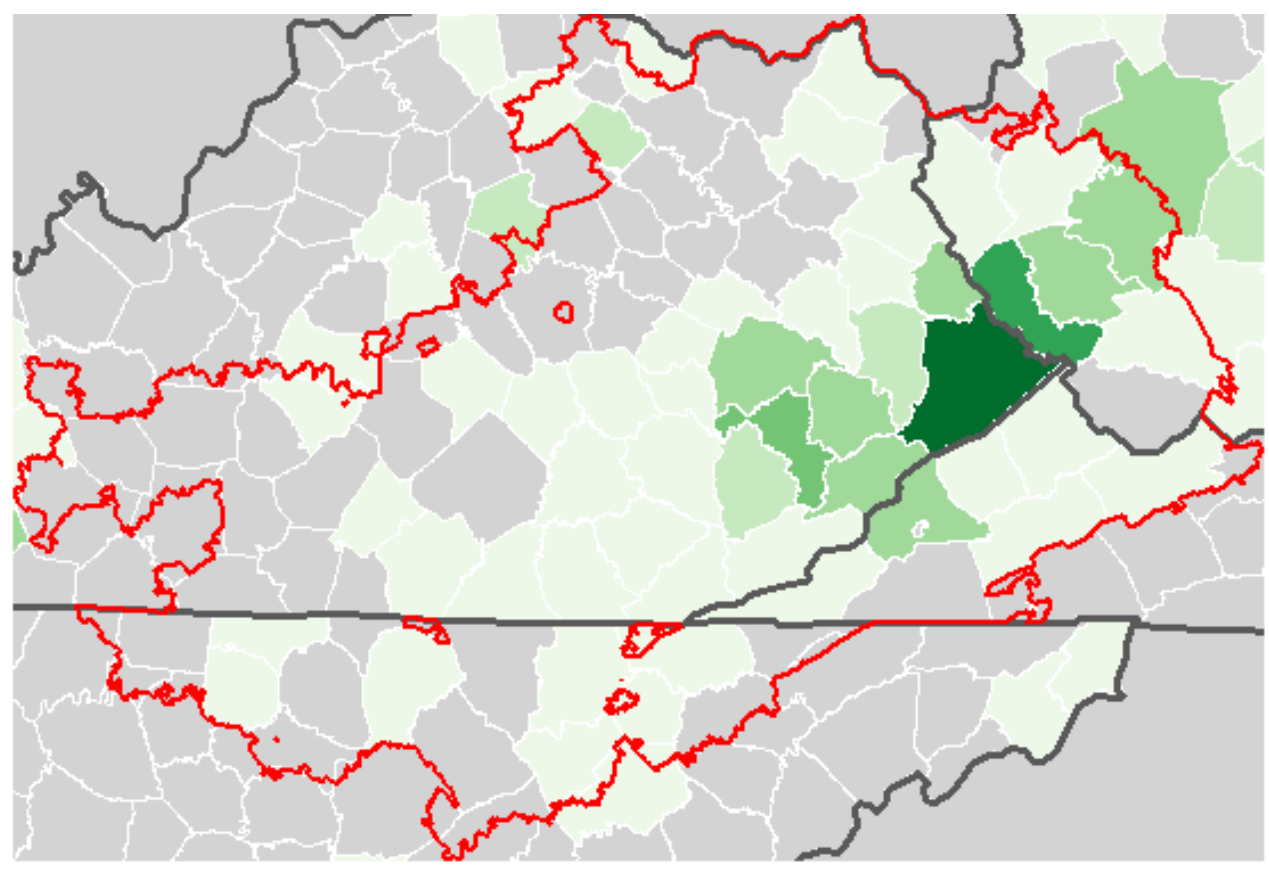

Coal Production (thousand tons)

\section{5}

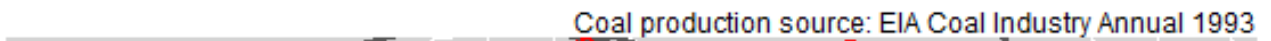

2000

4000

6000

8000

10,000

12,000
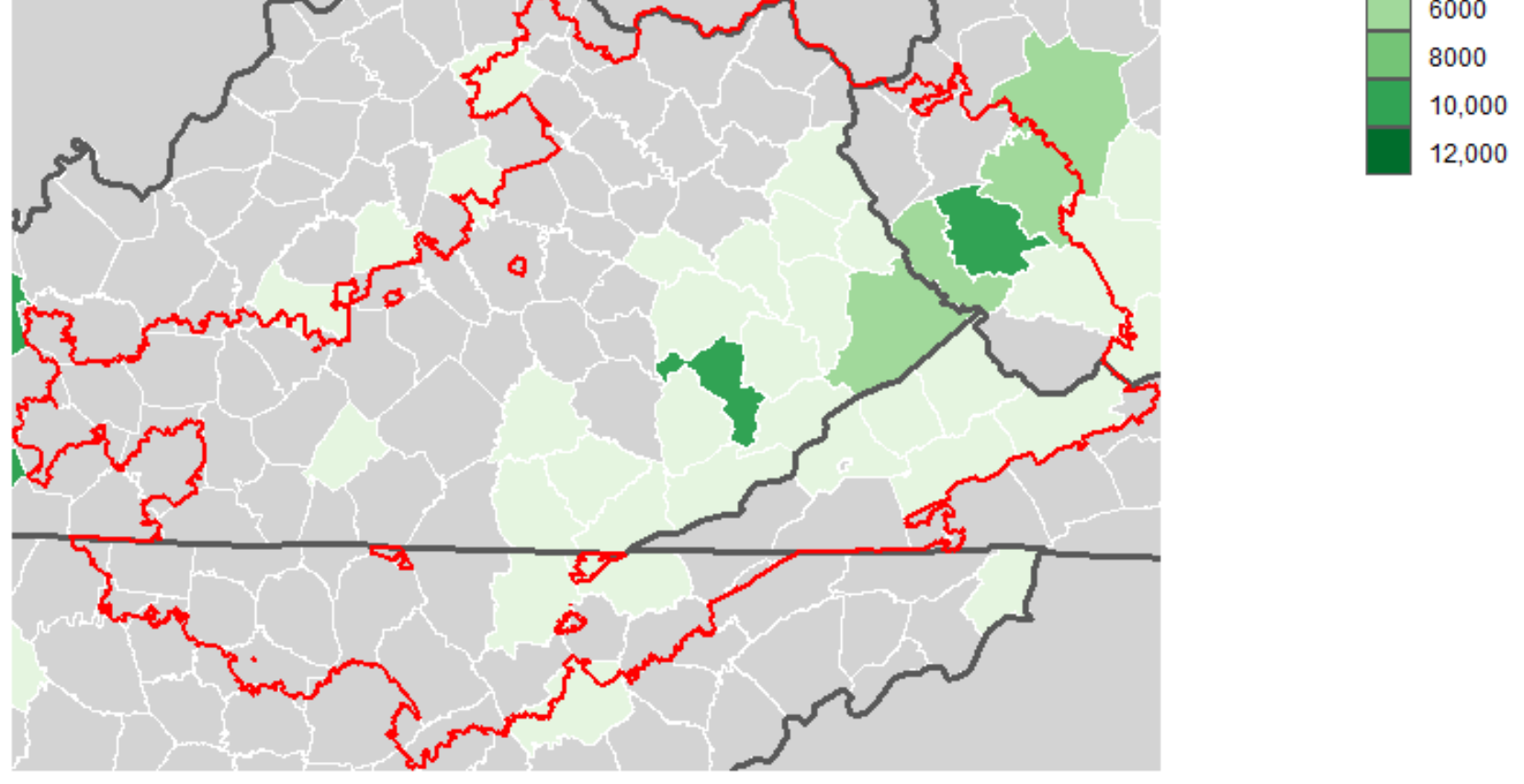

Coal production source: EIA Annual Coal Report 2015

\section{Figure 1}

Study area (red) and surface mining coal production (thousand tons) at the county level for 1993 (top) and 2015 (bottom). Coal production data for 2015 and 1993 were obtained from (19) and (20) 


\section{Air/water exposure $(m)$}

Surface mining $(x)$

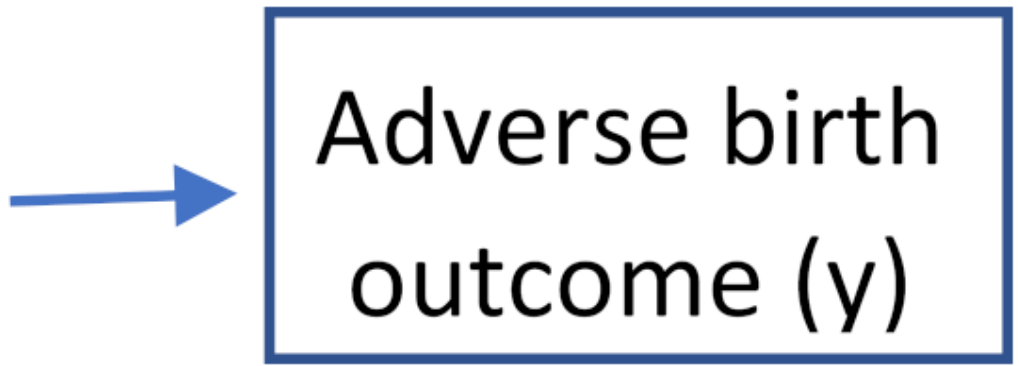

Figure 2

Directed acyclic graph outlining potential mediators of the association between surface mining and adverse birth outcomes. 


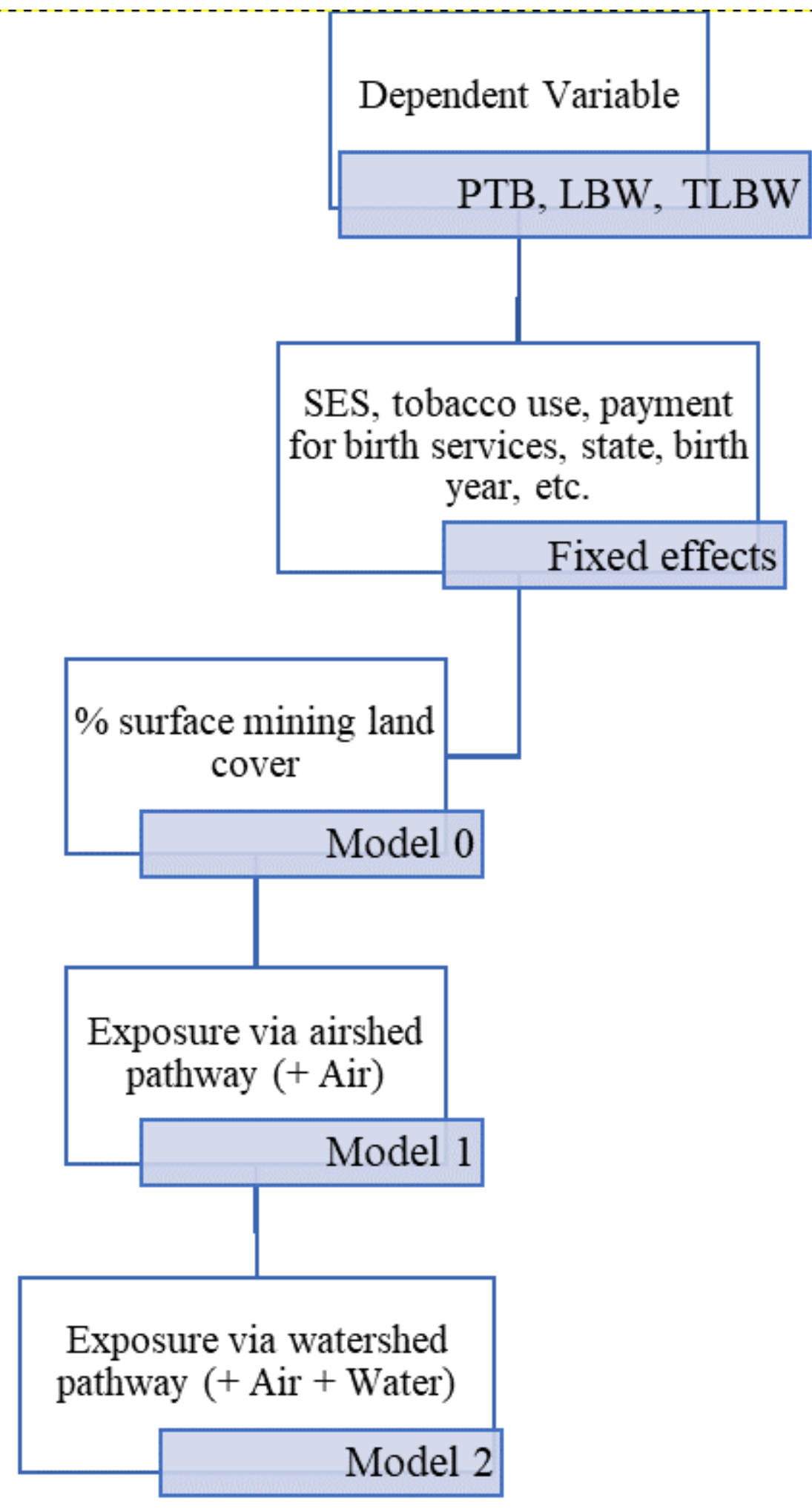

Figure 3

Model diagrams outlining the iterative model building process. Iterative models were built for each dependent variable (e.g., PTB, LBW, and TLBW). 


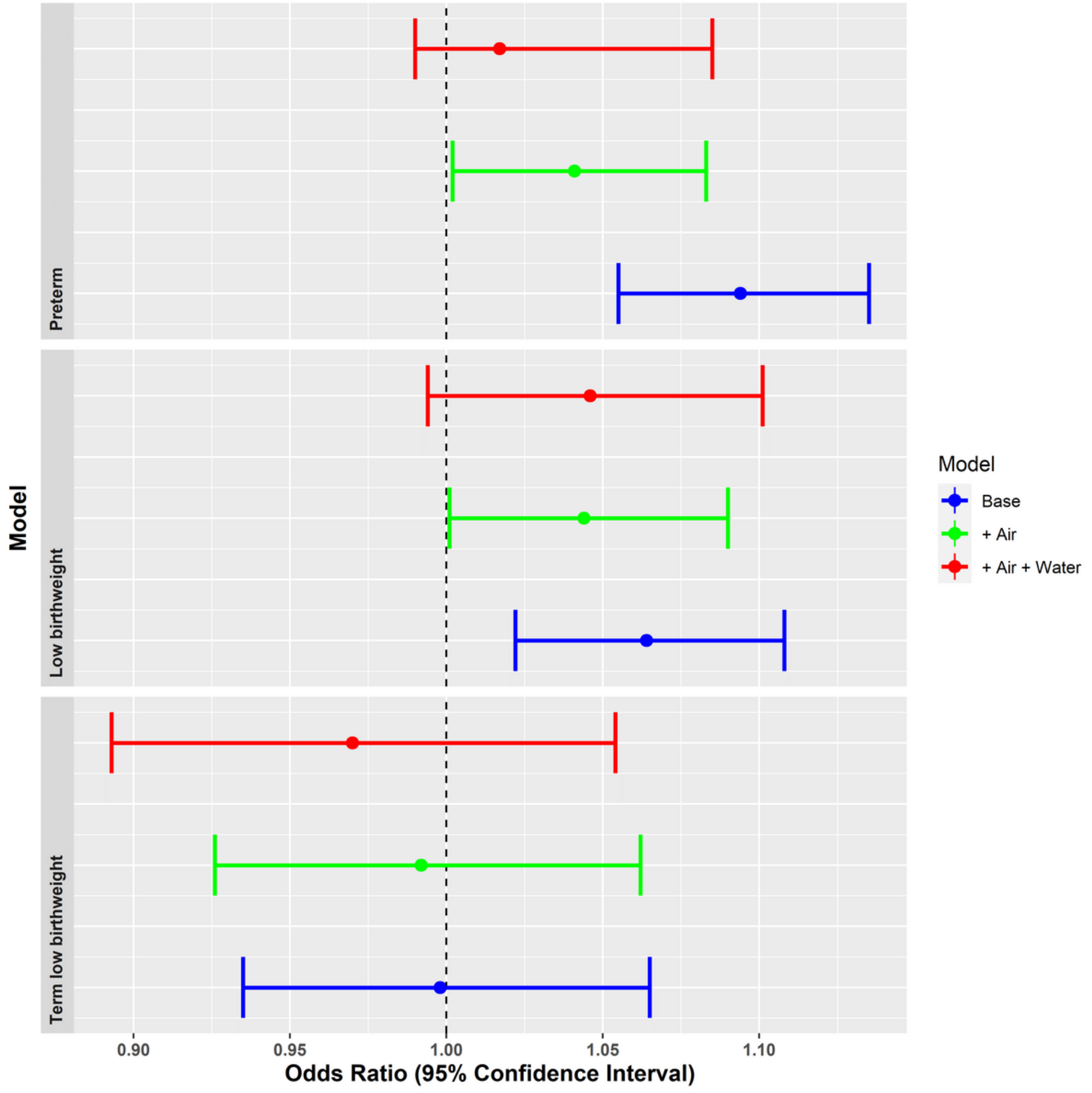

\section{Figure 4}

Odds ratios for proximity to active surface mining in predicting adverse birth outcomes. Blue represents the baseline model (no mediators); green represents the addition of the airshed mediator to the baseline model; red represents the addition of the watershed mediator to the baseline + airshed mediator model. Dots represent point estimates of odds ratios and lines represent upper and lower $95 \%$ confidence intervals. Lines crossing 1 indicate non-significance. 


\section{Supplementary Files}

This is a list of supplementary files associated with this preprint. Click to download.

- Supplementallnformation.docx 